\title{
Towards systemic sclerosis and away from primary biliary cirrhosis: the case of PTPN22
}

\author{
Daniel S. Smyk • Maria G. Mytilinaiou • \\ Piotr Milkiewicz • Eirini I. Rigopoulou • \\ Pietro Invernizzi $\cdot$ Dimitrios P. Bogdanos
}

Received: 16 July 2011/ Accepted: 29 July 2011/Published online: 7 September 2011

(C) Springer-Verlag 2011

\begin{abstract}
Primary biliary cirrhosis (PBC) is a chronic cholestatic liver disease characterized by immune-mediated destruction of the small and medium size intrahepatic bile ducts. PBC patients often have concomitant autoimmune diseases, which are most often autoimmune thyroid disease, as well as Sicca syndrome. Occasionally, some PBC patients will also have systemic sclerosis of the limited cutaneous type (lcSSc). Conversely, up to one-fourth of SSc patients are positive for antimitochondrial antibody, the serologic hallmark of PBC. It is also common for SSc patients to have concomitant autoimmune disease, which may include PBC in rare cases. This has led to speculation of shared environmental and/or genetic factors, which lead
\end{abstract}

D. S. Smyk · M. G. Mytilinaiou · D. P. Bogdanos $(\bowtie)$

Institute of Liver Studies, King's College London School

of Medicine at King's College Hospital, Denmark Hill Campus,

London SE5 9RS, UK

e-mail: dimitrios.bogdanos@kcl.ac.uk;

dimitrios.bogdanos@nhs.net

URL: http://www.bogdanoslab.com

P. Milkiewicz

Liver Unit, Liver Unit and Liver Research Laboratories, Pomeranian Medical University, SPSK2, Powstancow Wlkp, 7270-111 Szczecin, Poland

\section{E. I. Rigopoulou}

Department of Medicine and Research Laboratory of Internal Medicine, University of Thessaly Medical School, Thessaly, Mezourlo, Larissa 41222, Greece

\section{P. Invernizzi}

Center for Autoimmune Liver Diseases, Division of Internal Medicine, IRCCS Istituto Clinico Humanitas, Rozzano, Italy

P. Invernizzi

Division of Rheumatology, Allergy and Clinical Immunology,

University of California at Davis, Davis, CA, USA to the development of PBC in SSc patients and vice versa. Recent genetic studies have revealed associations with several genes in both SSc and PBC. PTPN22 is one gene that has been associated with SSc, but not with PBC. It may be argued that some SSc patients with a particular genotype, which shares genes found in both conditions may develop PBC. Likewise, particular genes such as PTPN22 may infer susceptibility to SSc alone. The presence of PTPN22 may also contribute to the development of SSc in PBC patients. The lack of a large number of overlapping genes may, in part, explain the relative rarity of PBC with $\mathrm{SSc}$ and vice versa. This review will examine the literature surrounding the genetic associations of PBC and SSc, and the role of PTPN22 in particular.

Keywords Autoimmunity - Autoimmune disease . Bile ducts · Cholestasis · Liver - Immunology · Rheumatology

\section{Introduction}

Primary biliary cirrhosis (PBC) is a chronic cholestatic liver disease characterized by immune-mediated destruction of the small- and medium-sized bile ducts [1-3]. The prevalence of $\mathrm{PBC}$ ranges from 28 to 402 per million. PBC predominantly affects middle-aged women [4]. Recent studies indicate that the prevalence of PBC is rising [4-7]. The autoimmune pathogenesis of PBC is supported by a plethora of experimental and clinical data, such as the presence of autoreactive $\mathrm{T}$ cells in $\mathrm{PBC}$ patients, and serum autoantibodies characteristic of the disease [8-20].

High-titer serum antimitochondrial autoantibodies (AMA) are pathognomonic for PBC, being present in $90-95 \%$ of patients $[1-3,8,19,21-28]$, and seropositivity 
of AMA in asymptomatic patients is predictive of eventual disease development [4]. These autoantibodies are specific to the lipoylated domains within components of the 2-oxoacid dehydrogenase family of enzymes, particularly the E2 component of the pyruvate dehydrogenase complex (PDC-E2) [1-3, 8, 21-24, 28-31]. In addition to AMA, PBC-specific anti-nuclear autoantibodies (ANA) are present in approximately $30 \%$ of patients $[21,22,24,26,28-$ $30,32,33]$. There are several PBC-specific ANA patterns detected by indirect immunofluorescence, including the "multiple nuclear dot" and "nuclear membrane/rim" patterns [21, 29, 30, 32, 34]. In most cases, the "multiple nuclear dot" pattern corresponds to autoantibodies against Sp100, Sp140, promyelocytic leukaemia nuclear body proteins, and small ubiquitin-like modifiers $[5,21,33,35-$ 43]. The "nuclear envelope/rim" pattern corresponds to reactivities specific for gp210 and nucleoporin p62 [32, 33]. Up to $30 \%$ of PBC patients have both patterns, which demonstrate significant disease specificity. The recognition of these patterns is not easy, and may be confused with similar pattern. ANA may be present in PBC patients who are found to be AMA negative, in addition to asymptomatic individuals and family members of PBC patients [5, 21, 39-42, 44, 45].

The aetiology of PBC is unknown, however, it is believed that genetic susceptibility, and environmental factors are involved in concert [46-50]. A number of xenobiotics and infectious agents have been proposed to induce the disease in individuals who are genetically predisposed [46-50]. Studies in animal models of the disease have provided data to suggest that specific infectious and environmental triggers can induce $\mathrm{PBC}$-specific pathological features, probably by the mechanism of molecular mimicry [36, 46, 51-62]. This mechanism implies that microbial sequences mimicking self proteins are capable of inducing an immune response, which cross reacts with autoantigens inducing autoimmunity, and overt autoimmune disease [63-71]. This would occur in the setting of $\mathrm{T}$ regulatory impairment, particularly in susceptible individuals [72-77]. Presenting symptoms may include nonspecific symptoms such as pruritus and/or fatigue $[2,3]$. In more severe cases, the patients may present with jaundice and portal hypertension [2,3]. Most are asymptomatic and diagnosed incidentally during assessment for pruritus, fatigue or other extrahepatic conditions (commonly other autoimmune diseases), or during screening when a close family member is diagnosed with $\mathrm{PBC}[78,79]$. A diagnosis of $\mathrm{PBC}$ is made if two of the following three criteria are fulfilled: elevated alkaline phosphatase (ALP), the presence of serum AMA (titre $\geq 1: 40$ ), and characteristic liver histology $[2,3,80]$. Serum AMA may precede the onset of symptoms and/or biochemical evidence of disease by several years, and prospective studies suggest that
AMA-positive asymptomatic patients go on to develop PBC [4].

Primary biliary cirrhosis progresses over many decades, with an unpredictable progression pattern from patient to patient. In most of the cases, the disease progresses in a slow pace, but in minority the disease is rapidly progressive, leading to cirrhosis and liver failure within a few years. Some studies suggested that patients with PBCspecific ANA may progress faster than those without these autoantibodies [5, 21, 33, 35-41, 81, 82]. The introduction of medical treatment with ursodeoxycholic acid (UDCA) has greatly improved the life expectancy and quality of life of PBC patients. When UDCA is administered in early $\mathrm{PBC}$ at adequate doses $(13-15 \mathrm{mg} / \mathrm{kg} /$ day $)$, the disease progression is often altered, with many patients having a normal life expectancy $[83,84]$. Patients at the very end stages of the disease require liver transplantation [85]. Like other conditions of presumed autoimmune origin, the disease may re-occur several years after transplantation [86].

Concomitant autoimmune diseases are often found in patients with PBC [1-3] and 30-70\% of the patients have Sicca symptomatology, with or without formally diagnosed Sjögrens syndrome, as well as autoimmune thyroiditis [78, 87-89]. However, a small number of patients also have concomitant systemic sclerosis (SSc) [78, 87-89]. Additionally, $\mathrm{PBC}$ is the most common autoimmune liver disorder in SSc patients [78, 87-89]. Several factors may be involved which induce a small number of PBC patients to develop SSc, including environmental and genetic causes. This review will examine the genetic background behind PBC and SSc, and highlight those genes which are common to both diseases, as well as those which are exclusively present in each. Some genes serve as an example of how susceptibility can be inferred in one disease, while being protective in another. This raises the possibility that although several genes are important for the development of PBC, only a small number are involved in the pathogenesis of both PBC and SSc.

\section{Systemic sclerosis}

Systemic sclerosis is a systemic connective tissue disease characterized by vascular and immune dysfunction, with features of skin sclerosis and a potential involvement of other organs (kidney, esophagus, heart and lung are the most frequent targets). Liver involvement is relatively rare. The prevalence of scleroderma ranges from 50 to 200 per million, with a higher female preponderance [90, 91]. Clustering within families is observed, and the high frequency of other autoimmune disorders in families of patients with scleroderma suggests genetic involvement. In addition, infectious agents have been suggested as possible 
contributing factors in the development and progression of SSc, through the mechanism of molecular mimicry [92-94].

Autoantibodies associated with the limited cutaneous form of SSc include anticentromere antibody (ACA), antiTh/To, anti-U1-RNP, and PM/Scl [95]. The diffuse cutaneous form of SSc is characterized by topoisomerase I antibody (ATA, also known as anti-Scl-70), anti-RNA polymerase III and anti-U3-RNP [95]. ATA has been associated with severe lung disease in the diffuse form of SSc [95].

\section{$\mathrm{PBC}$ in SSc and SSc in PBC}

$\mathrm{PBC}$ is known to occur in a small number of patients with SSc [96], however, liver disease is not a significant feature of scleroderma, with liver disease being present in a higher proportion of controls in large studies [97, 98]. The association of SSc and PBC was first described in the context of PBC and limited scleroderma [99], which was followed by further case reports [100, 101]. The prevalence of clinically evident $\mathrm{PBC}$ was $2 \%$ in a series of 817 patients with SSc [102].

Two large cohorts of PBC patients estimated the prevalence of SSc in PBC to be approximately 8\% [103]. However, case reports [5, 51, 99-101, 104-112] and some series reported a prevalence of 3-50\% [96, 103, 105, 111, $113,114]$. Epidemiological studies on PBC note a small number of patients who also have SSc or scleroderma. One study found scleroderma in $1 \%$ of a cohort of French PBC patients, with $1 \%$ of their first degree relatives and $1 \%$ of controls also having scleroderma [87]. An American study found that $2 \%$ of $\mathrm{PBC}$ patients and $1 \%$ of their first degree relatives had scleroderma, which was found in none of the controls [78]. First degree relatives with scleroderma were more often sisters, followed by daughters [78, 88].

\section{Genetics of PBC}

As mentioned, there is an increased risk of developing PBC, as well as other autoimmune diseases, if a first degree relative is affected by the disease [78, 87-89]. This, and recent twin studies are suggestive of genetic influences which predispose an individual to not only PBC, but also to autoimmune disease. Twin studies have especially demonstrated the role of genetics in PBC [115]. Sixteen pairs of PBC twins were identified from a 1,400 family cohort from several worldwide centers, with eight $\mathrm{MZ}$ and eight DZ pairs [115]. Five of eight MZ pairs were concordant for PBC (63\%), all of which were female [115]. This reflects one of the highest concordance rates among all autoimmune disease where twin studies have been preformed. In support for the role of genetic factors in PBC are also the reported defects in sex chromosomes [116-118].

The genome wide association study (GWAS) has been instrumental in the understanding of the genetic basis of autoimmune disease [96]. In recent years, GWAS studies in PBC have implicated a number of genes as being associated with the disease [119, 120]. Before GWAS, several HLA haplotypes were identified among pairs of PBC patients or small clusters, however until recently the only common HLA haplotype seen widely was HLA-DR8 [13, 120, 121]. Tsuji and colleagues [38] identified HLA-DR8 in $29.4 \%$ of PBC patients [121] and Invernizzi reported that HLA-DR8 is associated with PBC in Italian cohorts [122]. Both Invernizzi et al. and Donaldson and colleagues have reported that HLA-DR11 confers protection from PBC in studies involving cohorts of Italian patients, but the former study was unable to identify HLA-DR11 as been negatively associated with PBC in a cohort from the UK [121, 122]. HLA-DR13 was found to be protective in both populations [120-122]. A GWAS carried out by Hirschfield et al. [123] involving $536 \mathrm{PBC}$ patients and 1,536 controls from Canada and USA, found associations with HLA and nonHLA loci. The strongest HLA association was with HLA DQB1 [123]. Non-HLA loci included two single-nucleotide polymorphisms (SNPs) at IL12A loci, and one SNP at the IL12RB2 locus [123]. Associations were also found with STAT4 and CTLA4, which have also been associated with rheumatoid arthritis and systemic lupus erythematosus, as well as other autoimmune diseases [124]. Similar findings were reported with IL12A and IL12RB in an Italian cohort [125]. Additionally, associations were made with HLA regions DRB1, DQA1, DQB1, and DQA2, as well as non-HLA regions such as IRF5, SPIB, and the IKZF3-ORMDL3 of chromosome 17q12-21 [125].

The identification of STAT4 is significant, as it is involved with IL12 signalling, and has been linked with other autoimmune diseases [125]. Although no association has been found between STAT4 and the autoimmune disease commonly found along with $\mathrm{PBC}$, it is of interest given its association with SSc (see below). Hirschfield et al. [126] have also identified associations with variants at IRF5-TNPO3, 17q12-21, and MMEL1. The most recent genetic study was carried out on a UK population of 1,840 PBC cases, and 5,163 controls [127]. That study confirmed previous associations with MMEL1, IL12RB2, IL12A, IRF5, ORMDL3, SPIB, and several MHC [127]. New associations were found with 12 other genes, including STAT4 [127]. In another study involving a cohort of Japanese PBC patients and controls, no association was found with IL12A, IRF5 or SPIB [128]. However, that study did find an association between PBC and 17q12-21 [128]. The same group of investigators went on to investigate whether 
the Fc receptor-like 3 (FCRL3) was associated with PBC in Japanese and Italian cohorts, as it has been found to be associated with several other autoimmune disease, especially in Japanese patients [129]. A significant association between FCRL3 and PBC was found in Japanese but not in Italian patients [129].

Although these studies provide us with (usually positive) associations, they do not give us insight as to whether susceptibility to specific genes is associated with disease severity. Thus, it is not clear as to whether the possession of an individual gene or multiple genes infers susceptibility to a more advanced, or aggressive form of the disease, or whether these genes can predict an unfavorable outcome over the course of the disease. As well, the presence of susceptibility genes may be predetermined by geographical location or origin/ethnicity (see below).

\section{Genetics of SSc}

Genome wide association studies have also contributed to the identification of several genes associated with SSc [130, 131]. Among Caucasian and Hispanic SSc patients, positive HLA associations include HLA-DRB1*1104, DQA1*0501, DQB1*0301, with negative associations in those groups being DRB1*0701, DQA1*0201, DQB1*0202, and DRB1*1501 [132]. Positive associations among African Americans have been found with HLA-DRB1*0804, DQA1*0501, and DQB1*0301 [132]. ACA positivity has been closely associated with HLA-DQB1*0501 [132], and ATA positivity has been associated with HLA-DRB1*1104 [132]. Non-HLA regions have also been identified in SSc, and include STAT4 [102, 131, 133-135], IRF5 [122, 131, 136], BANK1 [132, 137], TNSF4 [132], TBX21 [102], IL23R [102], and C8orf13-BLK [132] among others [131]. Two studies have also identified an interesting gene, PTPN22, with SSc in large cohorts of American and European patients [138, 139]. PTPN22 is of interest given its link with other autoimmune diseases (see below).

\section{Common genes in PBC and SSc}

Genes which have been identified in both PBC and SSc include STAT4 and IRF5 (Table 1). This raises the possibility that these genes are involved in the development of SSc in PBC patients, or PBC in SSc patients. As SSc in $\mathrm{PBC}$ is relatively uncommon, one would expect a low prevalence of STAT4 and/or IRF5 in PBC patients, and indeed, only weak associations have been made with STAT4 in PBC [124]. As well, STAT4 has been associated with ACA positivity in SSc patients [102, 132, 139]. This is of interest as a study by Akimoto and colleagues found that
Table 1 Positive and negative genes in primary biliary cirrhosis (PBC) and systemic sclerosis (SSc)

\begin{tabular}{lll}
\hline Gene & Primary biliary cirrhosis & Systemic sclerosis \\
\hline HLA & & - \\
DR8 & + & + \\
DR11 & - & + \\
DQB1 & + & + \\
DRB1 & + & - \\
DQA2 & + & + \\
DQA1 & + & \\
Non-HLA & & + \\
IRF5 & $+*$ & + \\
STAT4 & + & + \\
PTPN22 & - & - \\
SPIB & $+*$ & + \\
BANK1 & - & - \\
IL12A & $+*$ & - \\
IL12RB & + & - \\
MMEL1 & + & + \\
IL-23R & - & + \\
TNSF4 & - & - \\
CXCR5 & + & - \\
NKFB1 & + & \\
\hline
\end{tabular}

The major positive and negative genetic associations found for HLA and non-HLA genes identified in PBC and SSc are presented in simplified form. In a shared gene hypothesis, individuals with genetic characteristics shared between the two diseases, maybe at risk of developing one disease in addition to the other (such as STAT4). Likewise, certain genes infer susceptibility to only one disease in isolation (such as PTPN22 in SSc). As well, some genes may be positively associated with one disease, but protective against another disease (such as DR11 in PBC)

* No association found in Japanese patients: note that no consensus between studies has been reached for all genes and the most representative associations (positive or negative) are presented

$80 \%$ of PBC-SSc and $100 \%$ of PBC-SSc spectrum (not fulfilling the criteria for full $\mathrm{PBC}-\mathrm{SSc}$ ) were ACA-positive, compared to only $25 \%$ of PBC patients without SSc [5]. It would be of interest to see whether STAT4 is a feature found in the few PBC patients who develop SSc, and vice versa. What role IRF5 may play is unclear, as it is more commonly associated with the diffuse form of $\mathrm{SSc}$, and PBC-SSc is usually found in patients with the limited form of the disease. The small number of overlapping genes may explain the relative rarity of SSc in PBC and vice versa.

\section{PTPN22: towards SSc and away from PBC}

PTPN22 encodes an 807-amino acid residue found in haematopoietic stem cells $[140,141]$. Of relevance to the 
pathogenesis of SSc, PTPN22 is involved in T and B cell signaling, and has been associated with ATA positivity in Caucasian patients $[130,139]$. PTPN22 has been linked with altered $\mathrm{T}$ and $\mathrm{B}$ cell function, including decreased CD4+ T and B cell activation, and a shift in memory $\mathrm{T}$ and B cell populations $[142,143]$. The presence of PTPN22 in association with SSc is not surprising, given that it has been implicated in multiple other autoimmune diseases. Associations with PTPN22 have been made with rheumatoid arthritis [140, 144, 145], juvenile idiopathic arthritis [146, 147], systemic lupus erythematosus [148, 149], autoimmune thyroid disease [27, 150, 151], myasthenia gravis [152], vitiligo [153], Addison's disease [154], and alopecia areata [155].

Given that PTPN22 has been associated with other autoimmune associations, a study speculated that this gene may confer susceptibility to PBC [156]. These investigators have studied a Canadian cohort of 160 Caucasian PBC, all AMA-positive, which were genotyped for the PTPN22 (C1858T) SNP, and they compared their results with those obtained in 290 demographically matched, healthy controls [156]. No association was found between the PTPN22 (1858T) allele and PBC, with a frequency of $7.5 \%$ in PBC patients compared to $8.4 \%$ in the controls [156]. There was also no significant association between PTPN22 and PBC patients with concomitant autoimmune disease [156]. Of note, 10 patients $(6 \%$ of the cohort) had concomitant scleroderma, but it is unknown as to whether these patients were among the small group of patients with the PTPN22 (1858T) allele.

Given the geographical differences seen in terms of how some genes function $[121,122,128,129]$, it may be the case that these differences relate to the prevalence of autoimmune disease in particular geographical locations. PBC, as well as other autoimmune disease, have been found to have higher prevalence rates in countries with more northern latitudes, such as the UK and Finland [4-7]. The studies by the groups of Donaldson and Invernizzi $[121,122]$ have shown that protective genes for PBC are more prevalent among Italians (southern latitude), compared to their more northern neighbors in the UK. As well, differences in associated genes have been found between Japanese and Italian cohorts [128, 129]. The prevalence of disease associated genes in relation to geographical location is not currently well defined. As PTPN22 is associated with multiple autoimmune diseases, it could be argued that the prevalence of PTPN22 may be increased in regions where there is a high rate of autoimmune diseases, including PBC. These differences may be present both geographically, as well as ethnically. Indeed, PTPN22 has been found to be more frequent in northern countries, with a gradual decrease in frequency with decreasing latitude [157]. Finland and Ukraine have the highest PTPN22 frequencies at 15 and $14.1 \%$, respectively [157]. Moving more south, the frequency in France and Spain is approximately $7 \%$, and lowest in Italy with a frequency of $2 \%$ [157]. Begovich and colleagues [140] note that PTPN22 is virtually absent in African and Asian populations, but has a frequency of 6-9\% in American and Australian Caucasians with European ancestry. This distribution rate may also play a role in the regulation of susceptibility to certain infectious agents, some of which may be implicated in the pathogenesis of autoimmune disease, including PBC and SSc $[11,158,159]$.

A relationship with infection has also been indicated with PTPN22, which is of interest given theories surrounding infection and molecular mimicry in the pathogenesis of autoimmune diseases. A particular variant of PTPN22, R620W, has been suggested to be protective against tuberculosis infection [134, 160-162]. However, PTPN22 has been found to increase susceptibility to infection by invasive bacteria such as pneumococcus [163]. Further characterization of the relationship between PTPN22 and infection may provide some clues as to the link between autoimmune disease and infectious agent.

\section{Conclusions}

The GWAS has provided numerous genes to be associated with PBC and SSc, a number of which are found in both conditions. This raises the question as to whether these shared genes are involved in the pathogenesis of SSc in PBC patients, or PBC in SSc patients. It may be argued that implicated genes, which do overlap between the two conditions, are responsible, or at least play a role, in the development of each disease in isolation. For example, PTPN22 has been associated with the development of SSc and other autoimmune diseases but not PBC. If an individual had a particular PTPN22 disease-associated allele (in addition to other SSc-specific genes) along with the appropriate environment, than that individual may develop SSc in isolation, or with concomitant autoimmune disease associated with PBC. That individual would likely not develop PBC. If, however, that individual also had alleles such as STAT4 (or others associated with PBC, or PBC and $\mathrm{SSc}$ ), then that individual may develop $\mathrm{PBC}$, given the appropriate environmental stimuli.

It is likely that further genetic associations will demonstrate a link between PBC, and autoimmune disease that $\mathrm{PBC}$ is associated with. As well, associations may also account for the fact that family members of PBC patients also have a higher frequency of $\mathrm{PBC}$ and other autoimmune disease. In addition to genetic factors, common environmental factors such as pathogens may also be shared between PBC and SSc, which may also contribute to 
the development of PBC-SSc in genetically susceptible individuals.

Conflict of interest None of the authors has a conflict of interest to declare.

\section{References}

1. Kaplan MM, Gershwin ME (2005) Primary biliary cirrhosis. N Engl J Med 353:1261-1273

2. Hohenester S, Oude-Elferink RP, Beuers U (2009) Primary biliary cirrhosis. Semin Immunopathol 3:283-307

3. Neuberger J (1997) Primary biliary cirrhosis. Lancet 350:875-879

4. James OF, Bhopal R, Howel D et al (1999) Primary biliary cirrhosis once rare, now common in the United Kingdom? Hepatology 30:390-394

5. Akimoto S, Ishikawa O, Takagi $\mathrm{H}$ et al (1998) Immunological features of patients with primary biliary cirrhosis (PBC) overlapping systemic sclerosis: a comparison with patients with PBC alone. J Gastroenterol Hepatol 13:897-901

6. Sood S, Gow PJ, Christie JM et al (2004) Epidemiology of primary biliary cirrhosis in Victoria, Australia: high prevalence in migrant populations. Gastroenterology 127:470-475

7. Rautiainen H, Salomaa V, Niemela S et al (2007) Prevalence and incidence of primary biliary cirrhosis are increasing in Finland. Scand J Gastroenterol 42:1347-1353

8. Bogdanos DP, Baum H, Vergani D (2003) Antimitochondrial and other autoantibodies. Clin Liver Dis 7:759-777, vi

9. Bogdanos DP, Baum H, Vergani D et al (2010) The role of $E$. coli infection in the pathogenesis of primary biliary cirrhosis. Dis Markers 29:301-311

10. Bogdanos DP, Vergani D (2006) Origin of cross-reactive autoimmunity in primary biliary cirrhosis. Liver Int 26:633-635

11. Koutsoumpas A, Mytilinaiou M, Polymeros D et al (2009) AntiHelicobacter pylori antibody responses specific for VacA do not trigger primary biliary cirrhosis-specific antimitochondrial antibodies. Eur J Gastroenterol Hepatol 21:1220

12. Gershwin ME, Mackay IR (1991) Primary biliary cirrhosis: paradigm or paradox for autoimmunity. Gastroenterology 100:822-833

13. Gershwin ME, Mackay IR (2008) The causes of primary biliary cirrhosis: convenient and inconvenient truths. Hepatology 47:737-745

14. Jones DE (2007) Pathogenesis of primary biliary cirrhosis. Gut $56: 1615-1624$

15. Mackay IR, Whittingham S, Fida S et al (2000) The peculiar autoimmunity of primary biliary cirrhosis. Immunol Rev 174:226-237

16. Shimoda S, Nakamura M, Ishibashi $\mathrm{H}$ et al (1995) HLA DRB4 0101-restricted immunodominant $\mathrm{T}$ cell autoepitope of pyruvate dehydrogenase complex in primary biliary cirrhosis: evidence of molecular mimicry in human autoimmune diseases. J Exp Med 181:1835-1845

17. Shimoda S, Nakamura M, Shigematsu H et al (2000) Mimicry peptides of human PDC-E2 163-176 peptide, the immunodominant T-cell epitope of primary biliary cirrhosis. Hepatology 31:1212-1216

18. Shimoda S, Van de Water J, Ansari A et al (1998) Identification and precursor frequency analysis of a common $\mathrm{T}$ cell epitope motif in mitochondrial autoantigens in primary biliary cirrhosis. J Clin Invest 102:1831-1840

19. Vergani D, Bogdanos DP (2003) Positive markers in AMAnegative PBC. Am J Gastroenterol 98:241-243
20. Bogdanos DP, Vergani D (2006) Origin of cross-reactive autoimmunity in primary biliary cirrhosis. Liver Int 26(6):633-635

21. Bogdanos DP, Invernizzi P, Mackay IR et al (2008) Autoimmune liver serology: current diagnostic and clinical challenges. World J Gastroenterol 14(21):3374-3387

22. Bogdanos DP, Komorowski L (2011) Disease-specific autoantibodies in primary biliary cirrhosis. Clin Chim Acta 412:502512

23. Dahnrich C, Pares A, Caballeria L et al (2009) New ELISA for detecting primary biliary cirrhosis-specific antimitochondrial antibodies. Clin Chem 55:978-985

24. Liu H, Norman GL, Shums Z et al (2010) PBC screen: an IgG/ IgA dual isotype ELISA detecting multiple mitochondrial and nuclear autoantibodies specific for primary biliary cirrhosis. J Autoimmun 35:436-442

25. Ma Y, Thomas MG, Okamoto M et al (2002) Key residues of a major cytochrome P4502D6 epitope are located on the surface of the molecule. J Immunol 169:277-285

26. Rigopoulou EI, Davies ET, Bogdanos DP et al (2007) Antimitochondrial antibodies of immunoglobulin G3 subclass are associated with a more severe disease course in primary biliary cirrhosis. Liver Int 27:1226-1231

27. Velaga MR, Wilson V, Jennings CE et al (2004) The codon 620 tryptophan allele of the lymphoid tyrosine phosphatase (LYP) gene is a major determinant of Graves' disease. J Clin Endocrinol Metab 89:5862-5865

28. Invernizzi P, Lleo A, Podda M (2007) Interpreting serological tests in diagnosing autoimmune liver diseases. Semin Liver Dis 27:161-172

29. Bogdanos DP, Mieli-Vergani G, Vergani D (2009) Autoantibodies and their antigens in autoimmune hepatitis. Semin Liver Dis 29:241-253

30. Mytilinaiou MG, Bogdanos DP (2009) Primary biliary cirrhosisspecific autoantibodies in patients with systemic sclerosis. Dig Liver Dis 41:916 (author reply 916-917)

31. Rigopoulou EI, Bogdanos DP, Liaskos C et al (2007) Antimitochondrial antibody immunofluorescent titres correlate with the number and intensity of immunoblot-detected mitochondrial bands in patients with primary biliary cirrhosis. Clin Chim Acta 380:118-121

32. Courvalin JC, Worman HJ (1997) Nuclear envelope protein autoantibodies in primary biliary cirrhosis. Semin Liver Dis 17:79-90

33. Invernizzi P, Selmi C, Ranftler C et al (2005) Antinuclear antibodies in primary biliary cirrhosis. Semin Liver Dis 25:298-310

34. Szostecki C, Guldner HH, Will H (1997) Autoantibodies against "nuclear dots" in primary biliary cirrhosis. Semin Liver Dis 17:71-78

35. Dubel L, Tanaka A, Leung PS et al (1999) Autoepitope mapping and reactivity of autoantibodies to the dihydrolipoamide dehydrogenase-binding protein (E3BP) and the glycine cleavage proteins in primary biliary cirrhosis. Hepatology 29:1013-1018

36. Wu SJ, Yang YH, Tsuneyama K et al (2011) Innate immunity and primary biliary cirrhosis: activated invariant natural killer $\mathrm{T}$ cells exacerbate murine autoimmune cholangitis and fibrosis. Hepatology 53:915-925

37. Palmer JM, Jones DE, Quinn J et al (1999) Characterization of the autoantibody responses to recombinant E3 binding protein (protein $\mathrm{X}$ ) of pyruvate dehydrogenase in primary biliary cirrhosis. Hepatology 30:21-26

38. Tsuji K, Watanabe Y, Van De Water J et al (1999) Familial primary biliary cirrhosis in Hiroshima. J Autoimmun 13:171178

39. Bogdanos DP, Liaskos C, Pares A et al (2007) Anti-gp210 antibody mirrors disease severity in primary biliary cirrhosis. Hepatology 45:1583 (author reply 1583-1584) 
40. Invernizzi P, Podda M, Battezzati PM et al (2001) Autoantibodies against nuclear pore complexes are associated with more active and severe liver disease in primary biliary cirrhosis. J Hepatol 34:366-372

41. Nakamura M, Kondo H, Mori T et al (2007) Anti-gp210 and anti-centromere antibodies are different risk factors for the progression of primary biliary cirrhosis. Hepatology 45:118-127

42. Rigopoulou EI, Davies ET, Pares A et al (2005) Prevalence and clinical significance of isotype specific antinuclear antibodies in primary biliary cirrhosis. Gut 54:528-532

43. Bogdanos DP, Vergani D, Muratori P et al (2004) Specificity of anti-sp100 antibody for primary biliary cirrhosis. Scand J Gastroenterol 39:405-406 (author reply 407)

44. Bogdanos DP, Liaskos C, Rigopoulou EI et al (2006) Antimitochondrial antibodies in patients with systemic lupus erythematosus: revealing the unforeseen. Clin Chim Acta 373:183-184 (author reply 185)

45. Bogdanos DP, Gilbert D, Bianchi I et al (2004) Antibodies to soluble liver antigen and alpha-enolase in patients with autoimmune hepatitis. J Autoimmune Dis 1:4

46. Invernizzi P, Selmi C, Gershwin ME (2010) Update on primary biliary cirrhosis. Dig Liver Dis 42:401-408

47. Selmi C, Invernizzi P, Zuin M et al (2005) Genetics and geoepidemiology of primary biliary cirrhosis: following the footprints to disease etiology. Semin Liver Dis 25:265-280

48. Selmi C, Invernizzi P, Zuin $M$ et al (2005) Genes and (auto)immunity in primary biliary cirrhosis. Genes Immun 6:543-556

49. Smyk D, Cholongitas E, Kriese S et al (2011) Primary biliary cirrhosis: family stories. Autoimmune Dis 2011:189585

50. Smyk D, Rigopoulou EI, Baum H et al (2011) Autoimmunity and environment: am I at risk? Clin Rev Allergy Immunol

51. Chuang YH, Ridgway WM, Ueno Y et al (2008) Animal models of primary biliary cirrhosis. Clin Liver Dis 12:333-347

52. Hirschfield GM, Gershwin ME (2011) Primary biliary cirrhosis: one disease with many faces. Isr Med Assoc J 13:55-59

53. Lleo A, Invernizzi P, Mackay IR et al (2008) Etiopathogenesis of primary biliary cirrhosis. World J Gastroenterol 14:33283337

54. Selmi C, Meda F, Kasangian A et al (2010) Experimental evidence on the immunopathogenesis of primary biliary cirrhosis. Cell Mol Immunol 7:1-10

55. Selmi C, Zuin M, Gershwin ME (2008) The unfinished business of primary biliary cirrhosis. J Hepatol 49:451-460

56. Vergani D, Bogdanos DP, Baum H (2004) Unusual suspects in primary biliary cirrhosis. Hepatology 39:38-41

57. Bogdanos DP, Pares A, Baum H et al (2004) Disease-specific cross-reactivity between mimicking peptides of heat shock protein of Mycobacterium gordonae and dominant epitope of E2 subunit of pyruvate dehydrogenase is common in Spanish but not British patients with primary biliary cirrhosis. J Autoimmun 22:353-362

58. Bogdanos D, Pusl T, Rust C et al (2008) Primary biliary cirrhosis following Lactobacillus vaccination for recurrent vaginitis. J Hepatol 49:466-473

59. Bogdanos DP, Baum H, Okamoto M et al (2005) Primary biliary cirrhosis is characterized by IgG3 antibodies cross-reactive with the major mitochondrial autoepitope and its Lactobacillus mimic. Hepatology 42:458-465

60. Van de Water J, Ishibashi H, Coppel RL et al (2001) Molecular mimicry and primary biliary cirrhosis: premises not promises. Hepatology 33:771-775

61. Baum H, Bogdanos DP, Vergani D (2001) Antibodies to Clp protease in primary biliary cirrhosis: possible role of a mimicking T-cell epitope. J Hepatol 34:785-787
62. Bogdanos DP, Baum H, Butler P et al (2003) Association between the primary biliary cirrhosis specific anti-sp100 antibodies and recurrent urinary tract infection. Dig Liver Dis 35:801-805

63. Muratori L, Bogdanos DP, Muratori P et al (2005) Susceptibility to thyroid disorders in hepatitis C. Clin Gastroenterol Hepatol 3:595-603

64. Wen L, Ma Y, Bogdanos DP et al (2001) Pediatric autoimmune liver diseases: the molecular basis of humoral and cellular immunity. Curr Mol Med 1:379-389

65. Polymeros D, Bogdanos DP, Day R et al (2006) Does crossreactivity between mycobacterium avium paratuberculosis and human intestinal antigens characterize Crohn's disease? Gastroenterology 131:85-96

66. Koutsoumpas A, Polymeros D, Tsiamoulos Z et al (2011) Peculiar antibody reactivity to human connexin 37 and its microbial mimics in patients with Crohn's disease. J Crohns Colitis 5:101-109

67. Bogdanos DP, Mieli-Vergani G, Vergani D (2000) Virus, liver and autoimmunity. Dig Liver Dis 32:440-446

68. Bogdanos DP, Vergani D (2009) Bacteria and primary biliary cirrhosis. Clin Rev Allergy Immunol 36:30-39

69. Bogdanos DP, Smith H, Ma Y et al (2005) A study of molecular mimicry and immunological cross-reactivity between hepatitis B surface antigen and myelin mimics. Clin Dev Immunol $12: 217-224$

70. Bogdanos DP, Dalekos GN (2008) Enzymes as target antigens of liver-specific autoimmunity: the case of cytochromes P450s. Curr Med Chem 15:2285-2292

71. Bogdanos DP, McFarlane IG (2003) Cytochrome P450 2A6 meets P450 2D6: an enigma of viral infections and autoimmunity. J Hepatol 39:860-863

72. Lan RY, Cheng C, Lian ZX et al (2006) Liver-targeted and peripheral blood alterations of regulatory $\mathrm{T}$ cells in primary biliary cirrhosis. Hepatology 43:729-737

73. Bernuzzi F, Fenoglio D, Battaglia F et al (2010) Phenotypical and functional alterations of CD8 regulatory $\mathrm{T}$ cells in primary biliary cirrhosis. J Autoimmun 35:176-180

74. Longhi MS, Ma Y, Bogdanos DP et al (2004) Impairment of $\mathrm{CD} 4(+) \mathrm{CD} 25(+)$ regulatory $\mathrm{T}$-cells in autoimmune liver disease. J Hepatol 41:31-37

75. Longhi MS, Ma Y, Mitry RR et al (2005) Effect of CD4+ $\mathrm{CD} 25+$ regulatory T-cells on CD8 T-cell function in patients with autoimmune hepatitis. J Autoimmun 25:63-71

76. Vergani D, Choudhuri K, Bogdanos DP et al (2002) Pathogenesis of autoimmune hepatitis. Clin Liver Dis 6:727-737

77. Vergani D, Longhi MS, Bogdanos DP et al (2009) Autoimmune hepatitis. Semin Immunopathol 31:421-435

78. Gershwin ME, Selmi C, Worman HJ et al (2005) Risk factors and comorbidities in primary biliary cirrhosis: a controlled interview-based study of 1032 patients. Hepatology 42:11941202

79. Hudson M, Rojas-Villarraga A, Coral-Alvarado P et al (2008) Polyautoimmunity and familial autoimmunity in systemic sclerosis. J Autoimmun 31:156-159

80. (2009) EASL Clinical Practice Guidelines: management of cholestatic liver diseases. J Hepatol 51:237-267

81. Itoh S, Ichida T, Yoshida T et al (1998) Autoantibodies against a $210 \mathrm{kDa}$ glycoprotein of the nuclear pore complex as a prognostic marker in patients with primary biliary cirrhosis. J Gastroenterol Hepatol 13:257-265

82. Lassoued K, Guilly MN, Andre C et al (1988) Autoantibodies to $200 \mathrm{kD}$ polypeptide(s) of the nuclear envelope: a new serologic marker of primary biliary cirrhosis. Clin Exp Immunol 74:283-288 
83. Poupon R (2010) Primary biliary cirrhosis: a 2010 update. J Hepatol 52:745-758

84. Corpechot C, Carrat F, Poupon R et al (2002) Primary biliary cirrhosis: incidence and predictive factors of cirrhosis development in ursodiol-treated patients. Gastroenterology 122:652-658

85. Milkiewicz P (2008) Liver transplantation in primary biliary cirrhosis. Clin Liver Dis 12:461-472

86. Schreuder TC, Hubscher SG, Neuberger J (2009) Autoimmune liver diseases and recurrence after orthotopic liver transplantation: what have we learned so far? Transpl Int 22:144-152

87. Corpechot C, Chretien Y, Chazouilleres O et al (2010) Demographic, lifestyle, medical and familial factors associated with primary biliary cirrhosis. J Hepatol 53:162-169

88. Parikh-Patel A, Gold EB, Worman H et al (2001) Risk factors for primary biliary cirrhosis in a cohort of patients from the United States. Hepatology 33:16-21

89. Prince MI, Ducker SJ, James OF (2010) Case-control studies of risk factors for primary biliary cirrhosis in two United Kingdom populations. Gut 59:508-512

90. Chifflot H, Fautrel B, Sordet C et al (2008) Incidence and prevalence of systemic sclerosis: a systematic literature review. Semin Arthritis Rheum 37:223-235

91. Le Guern V, Mahr A, Mouthon L et al (2004) Prevalence of systemic sclerosis in a French multi-ethnic county. Rheumatology (Oxford) 43:1129-1137

92. Radic M, Martinovic Kaliterna D, Radic J (2010) Infectious disease as aetiological factor in the pathogenesis of systemic sclerosis. Neth J Med 68:348-353

93. Grossman C, Dovrish Z, Shoenfeld Y et al (2011) Do infections facilitate the emergence of systemic sclerosis? Autoimmun Rev 10:244-247

94. Mora GF (2009) Systemic sclerosis: environmental factors. J Rheumatol 36:2383-2396

95. Steen VD (2005) Autoantibodies in systemic sclerosis. Semin Arthritis Rheum 35:35-42

96. Zenewicz LA, Abraham C, Flavell RA et al (2010) Unraveling the genetics of autoimmunity. Cell 140:791-797

97. D’Angelo WA, Fries JF, Masi AT et al (1969) Pathologic observations in systemic sclerosis (scleroderma). A study of fifty-eight autopsy cases and fifty-eight matched controls. Am J Med 46:428-440

98. Tuffanelli DL, Winkelmann RK (1961) Systemic scleroderma, a clinical study of 727 cases. Arch Dermatol 84:359-371

99. Murray-Lyon IM, Thompson RP, Ansell ID et al (1970) Scleroderma and primary biliary cirrhosis. Br Med J 3:258-259

100. Reynolds TB, Denison EK, Frankl HD et al (1971) Primary biliary cirrhosis with scleroderma, Raynaud's phenomenon and telangiectasia. New syndrome. Am J Med 50:302-312

101. O’Brien ST, Eddy WM, Krawitt EL (1972) Primary biliary cirrhosis associated with scleroderma. Gastroenterology 62:118-121

102. Gourh P, Agarwal SK, Divecha D et al (2009) Polymorphisms in TBX21 and STAT4 increase the risk of systemic sclerosis: evidence of possible gene-gene interaction and alterations in Th1/Th2 cytokines. Arthritis Rheum 60:3794-3806

103. Watt FE, James OF, Jones DE (2004) Patterns of autoimmunity in primary biliary cirrhosis patients and their families: a population-based cohort study. QJM 97:397-406

104. Brzezinska-Kolarz B, Undas A, Dyczek A et al (2001) Reynolds syndrome: the combination of scleroderma and primary biliary cirrhosis. Case report. Pol Arch Med Wewn 105:231-234

105. Clarke AK, Galbraith RM, Hamilton EB et al (1978) Rheumatic disorders in primary biliary cirrhosis. Ann Rheum Dis 37:42-47

106. Geffroy Y, Colin R, Hemet J et al (1973) Primary biliary cirrhosis and scleroderma. Med Chir Dig 2:281-286

107. Goring HD, Panzner M, Lakotta W et al (1998) Coincidence of scleroderma and primary biliary cirrhosis. Results of a systematic study of a dermatologic patient sample. Hautarzt 49:361-366

108. Maekawa S, Yano E, Shintani S (1992) A case of rheumatoid arthritis associated with progressive systemic sclerosis and primary biliary cirrhosis in the presence of various autoantibodies. Ryumachi 32:515-521

109. Invernizzi P, Miozzo M, Selmi C et al (2005) X chromosome monosomy: a common mechanism for autoimmune diseases. J Immunol 175:575-578

110. Powell FC, Schroeter AL, Dickson ER (1987) Primary biliary cirrhosis and the CREST syndrome: a report of 22 cases. Q J Med 62:75-82

111. Sherlock S, Scheuer PJ (1973) The presentation and diagnosis of 100 patients with primary biliary cirrhosis. N Engl J Med 289:674-678

112. Stadie V, Wohlrab J, Marsch WC (2002) Reynolds syndromea rare combination of 2 autoimmune diseases. Med Klin 97:40-43

113. Culp KS, Fleming CR, Duffy J et al (1982) Autoimmune associations in primary biliary cirrhosis. Mayo Clin Proc 57:365-370

114. Modena V, Marengo C, Amoroso A et al (1986) Primary biliary cirrhosis and rheumatic diseases: a clinical, immunological and immunogenetical study. Clin Exp Rheumatol 4:129-134

115. Selmi C, Mayo MJ, Bach N et al (2004) Primary biliary cirrhosis in monozygotic and dizygotic twins: genetics, epigenetics, and environment. Gastroenterology 127:485-492

116. Invernizzi P, Miozzo M, Battezzati PM et al (2004) Frequency of monosomy $\mathrm{X}$ in women with primary biliary cirrhosis. Lancet 363:533-535

117. Invernizzi P, Pasini S, Selmi C et al (2009) Female predominance and $\mathrm{X}$ chromosome defects in autoimmune diseases. J Autoimmun 33:12-16

118. Miozzo M, Selmi C, Gentilin B et al (2007) Preferential X chromosome loss but random inactivation characterize primary biliary cirrhosis. Hepatology 46:456-462

119. Hirschfield GM, Invernizzi P (2011) Progress in the genetics of primary biliary cirrhosis. Semin Liver Dis 31:147-156

120. Invernizzi $P$ (2011) Human leukocyte antigen in primary biliary cirrhosis: an old story now reviving. Hepatology 54:714-723

121. Donaldson PT, Baragiotta A, Heneghan MA et al (2006) HLA class II alleles, genotypes, haplotypes, and amino acids in primary biliary cirrhosis: a large-scale study. Hepatology 44:667-674

122. Invernizzi P, Battezzati PM, Crosignani A et al (2003) Peculiar HLA polymorphisms in Italian patients with primary biliary cirrhosis. J Hepatol 38:401-406

123. Hirschfield GM, Liu X, Xu C et al (2009) Primary biliary cirrhosis associated with HLA, IL12A, and IL12RB2 variants. N Engl J Med 360:2544-2555

124. Hemminki K, Li X, Sundquist K et al (2009) Shared familial aggregation of susceptibility to autoimmune diseases. Arthritis Rheum 60:2845-2847

125. Liu X, Invernizzi P, Lu Y et al (2010) Genome-wide metaanalyses identify three loci associated with primary biliary cirrhosis. Nat Genet 42:658-660

126. Hirschfield GM, Liu X, Han Y et al (2010) Variants at IRF5TNPO3, 17q12-21 and MMEL1 are associated with primary biliary cirrhosis. Nat Genet 42:655-657

127. Mells GF, Floyd JA, Morley KI et al (2011) Genome-wide association study identifies 12 new susceptibility loci for primary biliary cirrhosis. Nat Genet 43:329-332

128. Tanaka A, Invernizzi $\mathrm{P}$, Ohira $\mathrm{H}$ et al (2011) Replicated association of $17 q 12-21$ with susceptibility of primary biliary cirrhosis in a Japanese cohort. Tissue Antigens 78:65-68

129. Tanaka A, Ohira H, Kikuchi K et al (2011) Genetic association of $\mathrm{Fc}$ receptor-like 3 polymorphisms with susceptibility to 
primary biliary cirrhosis: ethnic comparative study in Japanese and Italian patients. Tissue Antigens 77:239-243

130. Dieude P, Boileau C, Allanore Y (2011) Immunogenetics of systemic sclerosis. Autoimmun Rev 10:282-290

131. Agarwal SK, Reveille JD (2010) The genetics of scleroderma (systemic sclerosis). Curr Opin Rheumatol 22:133-138

132. Gourh P, Agarwal SK, Martin E et al (2010) Association of the C8orf13-BLK region with systemic sclerosis in North-American and European populations. J Autoimmun 34:155-162

133. Dieude P, Guedj M, Wipff J et al (2009) STAT4 is a genetic risk factor for systemic sclerosis having additive effects with IRF5 on disease susceptibility and related pulmonary fibrosis. Arthritis Rheum 60:2472-2479

134. Lamsyah H, Rueda B, Baassi L et al (2009) Association of PTPN22 gene functional variants with development of pulmonary tuberculosis in Moroccan population. Tissue Antigens 74:228-232

135. Tsuchiya N, Kawasaki A, Hasegawa M et al (2009) Association of STAT4 polymorphism with systemic sclerosis in a Japanese population. Ann Rheum Dis 68:1375-1376

136. Dieude P, Guedj M, Wipff J et al (2009) Association between the IRF5 rs2004640 functional polymorphism and systemic sclerosis: a new perspective for pulmonary fibrosis. Arthritis Rheum 60:225-233

137. Dieude P, Wipff J, Guedj M et al (2009) BANK1 is a genetic risk factor for diffuse cutaneous systemic sclerosis and has additive effects with IRF5 and STAT4. Arthritis Rheum 60:3447-3454

138. Dieude P, Guedj M, Wipff J et al (2008) The PTPN22 620W allele confers susceptibility to systemic sclerosis: findings of a large case-control study of European Caucasians and a metaanalysis. Arthritis Rheum 58:2183-2188

139. Gourh P, Tan FK, Assassi S et al (2006) Association of the PTPN22 R620W polymorphism with anti-topoisomerase I- and anticentromere antibody-positive systemic sclerosis. Arthritis Rheum 54:3945-3953

140. Begovich AB, Carlton VE, Honigberg LA et al (2004) A missense single-nucleotide polymorphism in a gene encoding a protein tyrosine phosphatase (PTPN22) is associated with rheumatoid arthritis. Am J Hum Genet 75:330-337

141. Cohen S, Dadi H, Shaoul E et al (1999) Cloning and characterization of a lymphoid-specific, inducible human protein tyrosine phosphatase, Lyp. Blood 93:2013-2024

142. Aarnisalo J, Treszl A, Svec P et al (2008) Reduced CD4+T cell activation in children with type 1 diabetes carrying the PTPN22/ Lyp 620Trp variant. J Autoimmun 31:13-21

143. Rieck M, Arechiga A, Onengut-Gumuscu S et al (2007) Genetic variation in PTPN22 corresponds to altered function of T and B lymphocytes. J Immunol 179:4704-4710

144. Dieude P, Garnier S, Michou L et al (2005) Rheumatoid arthritis seropositive for the rheumatoid factor is linked to the protein tyrosine phosphatase nonreceptor 22-620W allele. Arthritis Res Ther 7:R1200-R1207

145. Michou L, Lasbleiz S, Rat AC et al (2007) Linkage proof for PTPN22, a rheumatoid arthritis susceptibility gene and a human autoimmunity gene. Proc Natl Acad Sci USA 104:1649-1654

146. Hinks A, Barton A, John S et al (2005) Association between the PTPN22 gene and rheumatoid arthritis and juvenile idiopathic arthritis in a UK population: further support that PTPN22 is an autoimmunity gene. Arthritis Rheum 52:1694-1699
147. Viken MK, Amundsen SS, Kvien TK et al (2005) Association analysis of the $1858 \mathrm{C}>\mathrm{T}$ polymorphism in the PTPN22 gene in juvenile idiopathic arthritis and other autoimmune diseases. Genes Immun 6:271-273

148. Kyogoku C, Langefeld CD, Ortmann WA et al (2004) Genetic association of the R620W polymorphism of protein tyrosine phosphatase PTPN22 with human SLE. Am J Hum Genet 75:504-507

149. Orozco G, Sanchez E, Gonzalez-Gay MA et al (2005) Association of a functional single-nucleotide polymorphism of PTPN22, encoding lymphoid protein phosphatase, with rheumatoid arthritis and systemic lupus erythematosus. Arthritis Rheum 52:219-224

150. Criswell LA, Pfeiffer KA, Lum RF et al (2005) Analysis of families in the multiple autoimmune disease genetics consortium (MADGC) collection: the PTPN22 620W allele associates with multiple autoimmune phenotypes. Am J Hum Genet 76:561-571

151. Smyth D, Cooper JD, Collins JE et al (2004) Replication of an association between the lymphoid tyrosine phosphatase locus (LYP/PTPN22) with type 1 diabetes, and evidence for its role as a general autoimmunity locus. Diabetes 53:3020-3023

152. Vandiedonck C, Capdevielle C, Giraud M et al (2006) Association of the PTPN22*R620W polymorphism with autoimmune myasthenia gravis. Ann Neurol 59:404-407

153. LaBerge GS, Bennett DC, Fain PR et al (2008) PTPN22 is genetically associated with risk of generalized vitiligo, but CTLA4 is not. J Invest Dermatol 128:1757-1762

154. Skinningsrud B, Husebye ES, Gervin K et al (2008) Mutation screening of PTPN22: association of the 1858T-allele with Addison's disease. Eur J Hum Genet 16:977-982

155. Betz RC, Konig K, Flaquer A et al (2008) The R620W polymorphism in PTPN22 confers general susceptibility for the development of alopecia areata. Br J Dermatol 158:389-391

156. Milkiewicz P, Pache I, Buwaneswaran H et al (2006) The PTPN22 1858T variant is not associated with primary biliary cirrhosis. Tissue Antigens 67:434-437

157. Burn GL, Svensson L, Sanchez-Blanco C et al (2011) Why is PTPN22 a good candidate susceptibility gene for autoimmune disease? FEBS Lett

158. Kalabay L, Fekete B, Czirjak L et al (2002) Helicobacter pylori infection in connective tissue disorders is associated with high levels of antibodies to mycobacterial hsp65 but not to human hsp60. Helicobacter 7:250-256

159. Bogdanos DP, Baum H, Gunsar F et al (2004) Extensive homology between the major immunodominant mitochondrial antigen in primary biliary cirrhosis and Helicobacter pylori does not lead to immunological cross-reactivity. Scand J Gastroenterol 39:981-987

160. Gomez LM, Anaya JM, Martin J (2005) Genetic influence of PTPN22 R620W polymorphism in tuberculosis. Hum Immunol 66:1242-1247

161. Lopez-Escamez JA (2010) A variant of PTPN22 gene conferring risk to autoimmune diseases may protect against tuberculosis. J Postgrad Med 56:242-243

162. Waisberg M, Tarasenko T, Vickers BK et al (2011) Genetic susceptibility to systemic lupus erythematosus protects against cerebral malaria in mice. Proc Natl Acad Sci USA 108:1122-1127

163. Chapman SJ, Khor CC, Vannberg FO et al (2006) PTPN22 and invasive bacterial disease. Nat Genet 38:499-500 